\title{
Effectiveness of Fuzzy Overlay Function for Multi-Criteria Spatial Modeling-A Case Study on Preparation of Land Resources Map for Mawsynram Block of East Khasi Hills District of Meghalaya, India
}

\author{
Priyanka Baidya, Dibyajyoti Chutia, Singuluri Sudhakar, Chandan Goswami, \\ Jonali Goswami, Victor Saikhom, Puyam S. Singh, Kamini Kanta Sarma \\ North Eastern Space Applications Centre, Department of Space, Government of India, Umiam, India \\ Email: d.chutia@nesac.gov.in
}

Received 14 September 2014; revised 10 October 2014; accepted 5 November 2014

Copyright (C) 2014 by authors and Scientific Research Publishing Inc.

This work is licensed under the Creative Commons Attribution International License (CC BY).

http://creativecommons.org/licenses/by/4.0/

(c) (i) Open Access

\begin{abstract}
Multi-criteria spatial modeling is one of the important components of spatial decision support system (SDSS). Multi-criteria spatial modeling often requires a common scale of values for diverse and dissimilar inputs to create an integrated analysis. Weighted overlay function is most commonly used for site suitability analysis which identifies the most preferred locations for a specific phenomenon. However, weighted overlay function gives inconsistent and erroneous results for highly dissimilar inputs as it assumes that most favorable factors result in the higher values of raster, while identifying the best sites. This paper conveys the effectiveness of fuzzy overlay function for multi-criteria spatial modeling. It is based on the principle of fuzzy logic theory which defines membership using Gaussian function on each of the input rasters instead of giving individual rank to them like in weighted overlay function. A case study on preparation of land resources map for Mawsynram block of East Khasi Hills district of Meghalaya, India is presented here. It was observed that fuzzy overlay function has given more satisfactory output in terms of site suitability while comparing with the result of weighted overlay function.
\end{abstract}

\section{Keywords}

Multi-Criteria Spatial Modeling, Spatial Decision Support System (SDSS), Weighted Overlay, Fuzzy Overlay 


\section{Introduction}

Spatial analysis in Geographic Information System (GIS) is a rapidly changing filed, which includes a variety of techniques, tools and different analytical approaches. Applicability or effectiveness of spatial analysis has been greatly improved by integration of various statistical methods for solving complex problem. The increasing ability to capture and handle geo-spatial data conveys that spatial analysis is mainly occurring within data-rich environment. However, spatial data come in many formats and it is not easy to arrive at a system of classification that is simultaneously exclusive, exhaustive, imaginative, and satisfying [1]. GIS facilitates an environment for managing the data and computing their spatial relationship.

Spatial analysis is an important component in multi-criteria spatial modeling. Multi-criteria spatial modeling often requires intervention of users for any need-based applications or services. The availability of relevant geo-spatial data and their influences or relevance are the main basis of spatial analysis for any kind of potential application. For example, the accessibility to services, facilities and amenities is an essential factor for evaluation of potential sites for infrastructure development [2] [3]. Spatial analysis has been effectively used to provide newer dimensions in identifying suitable sites for various horticultural crops and also for appropriate monitoring and management of land resources in an integrated manner with reference to agro-climatic condition [4]. Chutia 2010 developed an efficient election management system where multi-criteria modeling was used for identification of scientific location of polling stations [5]. Multi-criteria spatial modeling enabled by spatial analysis is one of the most efficient tools for development of spatial decision support system (SDSS). It not only improves the management, analysis and presentation of any SDSS, but also supports spatial analysis and modeling within the geographic and the other spatially defined data [6].

In this paper, we have demonstrated the applicability of multi-criteria spatial modeling for site suitability analysis. A case study on preparation of land resource map for Mawsynram block of East Khasi Hills district of Meghalaya, India is presented. Mawsynram block of Meghalaya has tremendous scope for expansion of horticultural and agro-horticultural activities. Since the land holdings of this region are small, the cultivators should be encouraged to move from subsistence farming to high-valued crops like vegetables, fruit, medicinal and aromatic plants. Cultivation of these crops requires more labour having knowledge of cultivation and need support of modern technologies, cold storage and marketing [7]. However, cultivators of the region need to be exposed scientifically about the capability of their own lands to make it more productive. Site suitability analysis of a land can be performed mainly based on the capability of the land, e.g. in terms of land use pattern, soil type, ground water prospect, climate and other scientific inputs. The main objective of this study is to establish the effectiveness of fuzzy logic for preparation of land resource map.

\section{Study Area}

Mawsynram block of East Khasi Hills district of Meghalaya covers an area of 828.74 Sq.km with a total population of 45,262 as per 2011 census. Mawsynram is one of the 8 blocks of East Khasi Hills district lies between $25^{\circ} 08^{\prime} \mathrm{N} \& 25^{\circ} 33^{\prime} \mathrm{N}$ Latitude and $91^{\circ} 21^{\prime} \mathrm{E} \& 91^{\circ} 45^{\prime} \mathrm{E}$ Longitude. The Mawsynram town is located at $51 \mathrm{~km}$ away from the state capital Shillong. Mawsynram features a subtropical highland climate with an extraordinarily rainy and lengthy monsoonal season. Based on the data of a recent few decades, it appears to be the wettest place in the world, or the place with the highest average annual rainfall. Mawsynram receives nearly $12 \mathrm{~m}$ of rainfall in an average year, and the vast majority of it falls during the monsoon months. The block has tremendous potential for expansion of both horticultural and agro-horticultural activities considering the typical geographical terrain and climate. Figure 1 depicts the satellite image of Mawsynram block as captured by LISS IV sensor of Resourcesat-1 satellite.

\section{Datasets and Methodology}

\subsection{Datasets Used}

Existing geo-spatial layers prepared under various national projects of Indian Space Research Organization (ISRO)/Department of Space (DOS) such as current land use land cover (LULC), land capability (LCAP), ground water prospects (GWP), sub-watershed prioritization (SWP) at 1:50 K scale have formed the core of primary input parameters for multi-criteria site suitability analysis. Mawsynram is mainly a hilly terrain represents a typical rural landscape of forest, tree clad areas, scrub forest, agriculture etc. Existing area statistics 


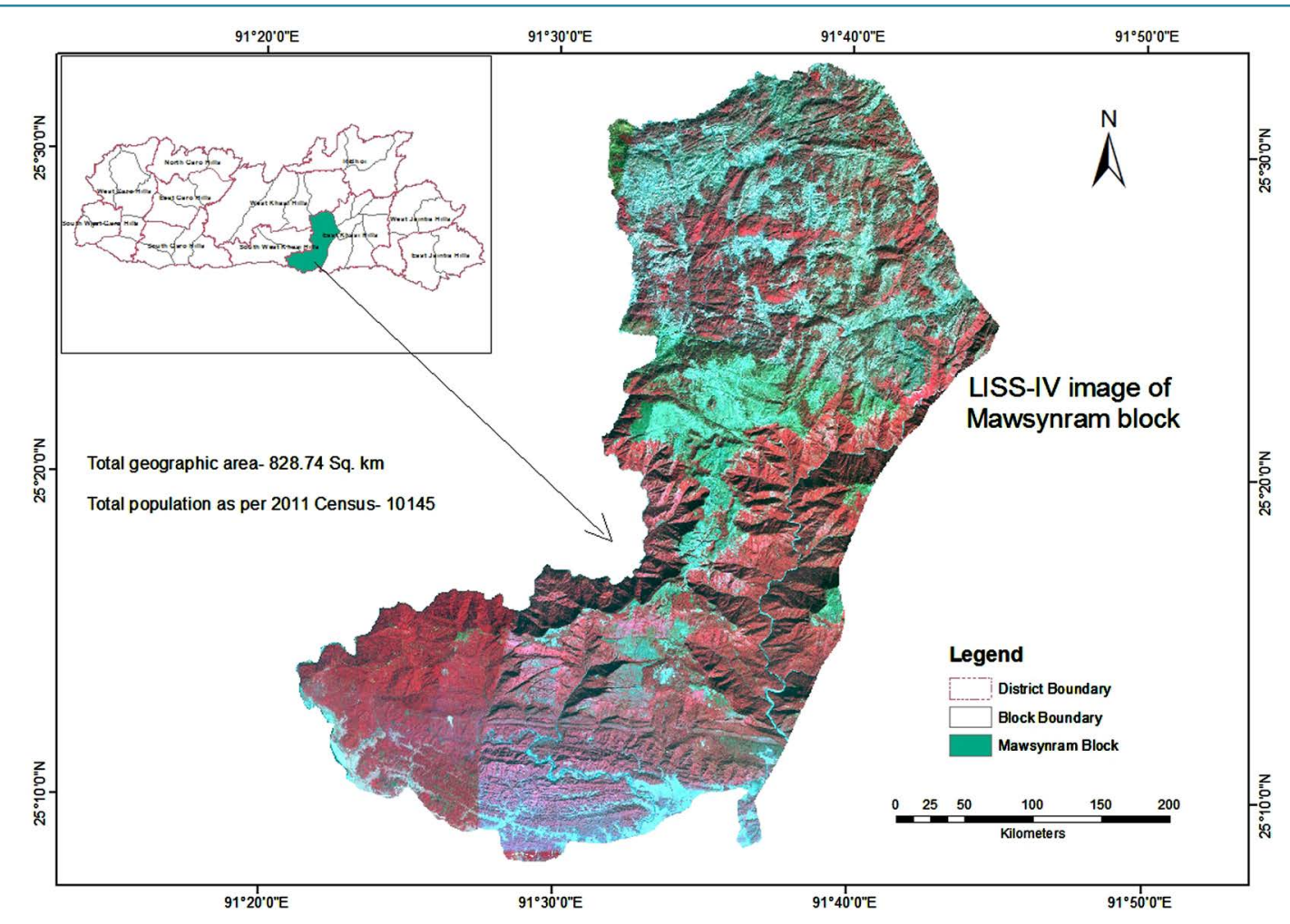

Figure 1. LISS IV image of Mawsynram block.

of land use is given in Table 1 and the corresponding land use map of Mawsynram block is shown in Figure 2.

\subsection{Methods}

We have adopted multi-criteria spatial modeling using weighted overlay function and fuzzy overlay function. Total four input layers, LULC, LCAP, GWP and SWP have been incorporated in the spatial model with their respective influence values and weightages. Higher value of influence in weighted overlay function indicates the importance of a layer in a particular site suitability analysis. For example, LULC and LCAP are given higher influences as compared to SWP and GWP while recommending intensive agriculture. On the other hand, fuzzy overlay function is not based on influence value; it requires weightage of fuzzy membership value to decide the suitable area. The proposed site suitability map for land resources planning is comprised of intensive agriculture (IA), agro-horticulture (AH), horticulture (H), aforestation (AF) and no change (NC). NC is basically comprised of built up area, water bodies, forest and non-culturable wastelands for which analysis was not carried out. Proximity to the existing roads and settlements is another important parameter while finalizing suitable sites. Total agricultural land in the study area is 5860.48 ha, whereas area falling under culturable wasteland is 31225.43 ha. Culturable wasteland is nothing but mainly comprised of scrublands, forest blank and tree clad areas (open) and few pockets of existing wastelands. Major influence was given to the agricultural land while recommending intensive agriculture followed by horticulture and agro-horticulture areas. On the other hand, culturable wasteland is more relevant as compared to the other land use classes for recommendation of aforestation, horticulture and agro-horticulture areas.

\subsubsection{Weighted Overlay}

Weighted overlay applies a common scale of values to diverse and dissimilar inputs to create an integrated analysis. Even within a single raster, we need to define the weightage values to the classes based on the relevance in the site suitability. The weighted overlay function weights the individual input raster on a defined scale (1 to 10). The more favourable locations for each input criterion will be reclassified to the higher values. In the weighted overlay tool, the influences assigned to all the input rasters must equal to 100 percent. The equation for weighted overlay function can be given as follows: 


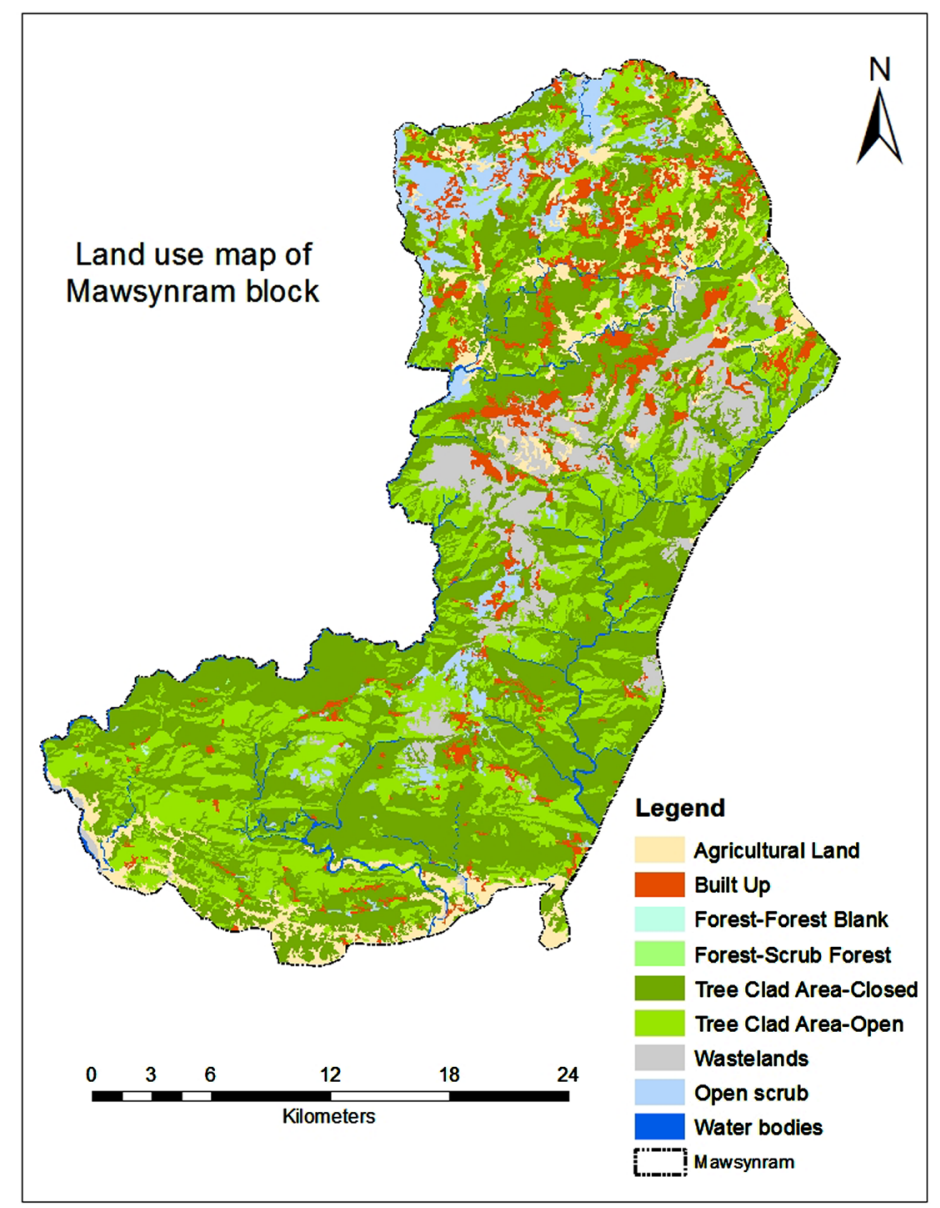

Figure 2. Land use map of Mawsynram block.

Table 1. Existing land use statistics.

\begin{tabular}{cc}
\hline Land Use Classes & Area (ha) \\
\hline Agricultural Land & 5860.48 \\
Built Up & 5657.06 \\
Forest Blank & 9.83 \\
Scrub Forest & 13.25 \\
Tree Clad Area-Closed & 38513.55 \\
Tree Clad Area-Open & 20618.73 \\
Wastelands & 10610.77 \\
Water Bodies & 1590.29 \\
Total & 82873.96 \\
\hline
\end{tabular}

$$
f(x)=\sum_{l=1}^{m} W_{l i} * I_{l}
$$

where, $m$ is the number of input raster,

$W_{l i}$ is the weightage value of $i$-th pixel of $l$-th layer,

$I_{l}$ is the percentage influence of $l$-th layer.

The layers are multiplied by the appropriate weightage, and for each cell, the resulting values are added to- 
gether. Weighted Overlay assumes that more favorable factors result in the higher values in the output raster, therefore identifying these locations as being the best. The flow chart of spatial modeling is given in the Figure 3.

\subsubsection{Fuzzy Overlay}

Fuzzy overlay analysis is based on set theory, where a set generally corresponds to a class. Fuzzy overlay analysis reclassifies or transforms the data values to a common scale, but the transformed values represents the probability of belonging to a specified. In weighted overlay and weighted sum, the values are on a ratio scale of preference, with the higher values being more favourable, unlike possibilities of membership as they are in fuzzy overlay. The combining analysis step in fuzzy overlay analysis quantifies each location's possibility of belonging to specified sets from various input rasters. The equation using fuzzy Gaussian function can be given as:

$$
\mu(x)=e^{-f_{1}^{*}\left(x-f_{2}\right)^{2}}
$$

where, the inputs to the equation $f_{1}$ and $f_{2}$ are the spread and the midpoint respectively.

Midpoint can be user-defined value with a fuzzy membership of 1 . The default is the midpoint of the range of values of the input raster. Spread defines the membership of the Gaussian function. It generally ranges from 0.01 to 1 . Increasing the spread causes the fuzzy membership curve to become steeper. Fuzzy overlay analysis quantifies the possibilities of each cell or location to a specified set based on membership value. The flow chart of multi-criteria spatial modeling using fuzzy overlay function is given in the Figure 4.

\section{Results and Discussion}

The main objective of this study is to establish the effectiveness of fuzzy logic for multi-criteria site suitability analysis. Here, site suitability analysis outputs the recommended areas based on certain criteria as discussed in the earlier sections. Both weighted overlay and fuzzy overlay function were used in the multi-criteria model. Any overlay function in a multi-criteria spatial model is considered to be effective if it satisfies all the input criteria for identification of suitable sites. Discussions on statistical summary of results followed by comparative evaluation of both the overlay functions are illustrated next.

Area statistics of land resources map derived from weighted overlay analysis is given in Table 2. Out of 5860.48 ha of existing agricultural land, intensive agriculture is proposed in 2992.37 ha areas. Major portion of the agricultural land is found suitable for intensive agriculture. However the land has tremendous potential for expansion of other agro-horticultural and horticultural activities. Out of 31225.43 ha of culturable wasteland, approximately 11760.76 ha area is found suitable for expansion of land resources planning activity. The area mentioned under "No Change" category (Table 2 and Table 3) are not feasible for above activities because of type of current land uses (e.g. barren rocky areas). Result of weighted overlay analysis shows that major portion of the culturable wastelands is cultivable and has good potential for mainly horticultural and other agro-horticultural activities. Around 123.86 ha areas of culturable wastelands are found suitable for intensive agriculture. The land resources map prepared using weighted overlay is depicted in the Figure 5.

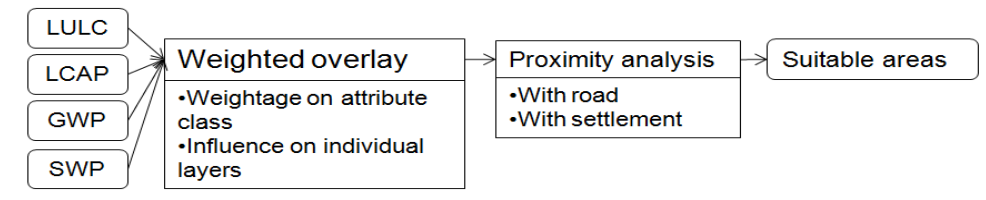

Figure 3. Flow chart of multi-criteria spatial modeling using weighted overlay function.

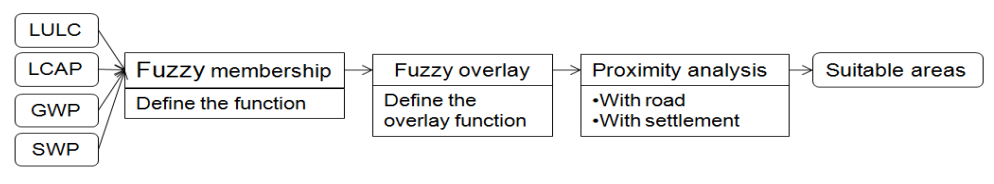

Figure 4. Flow chart of multi-criteria spatial modeling using fuzzy overlay function. 


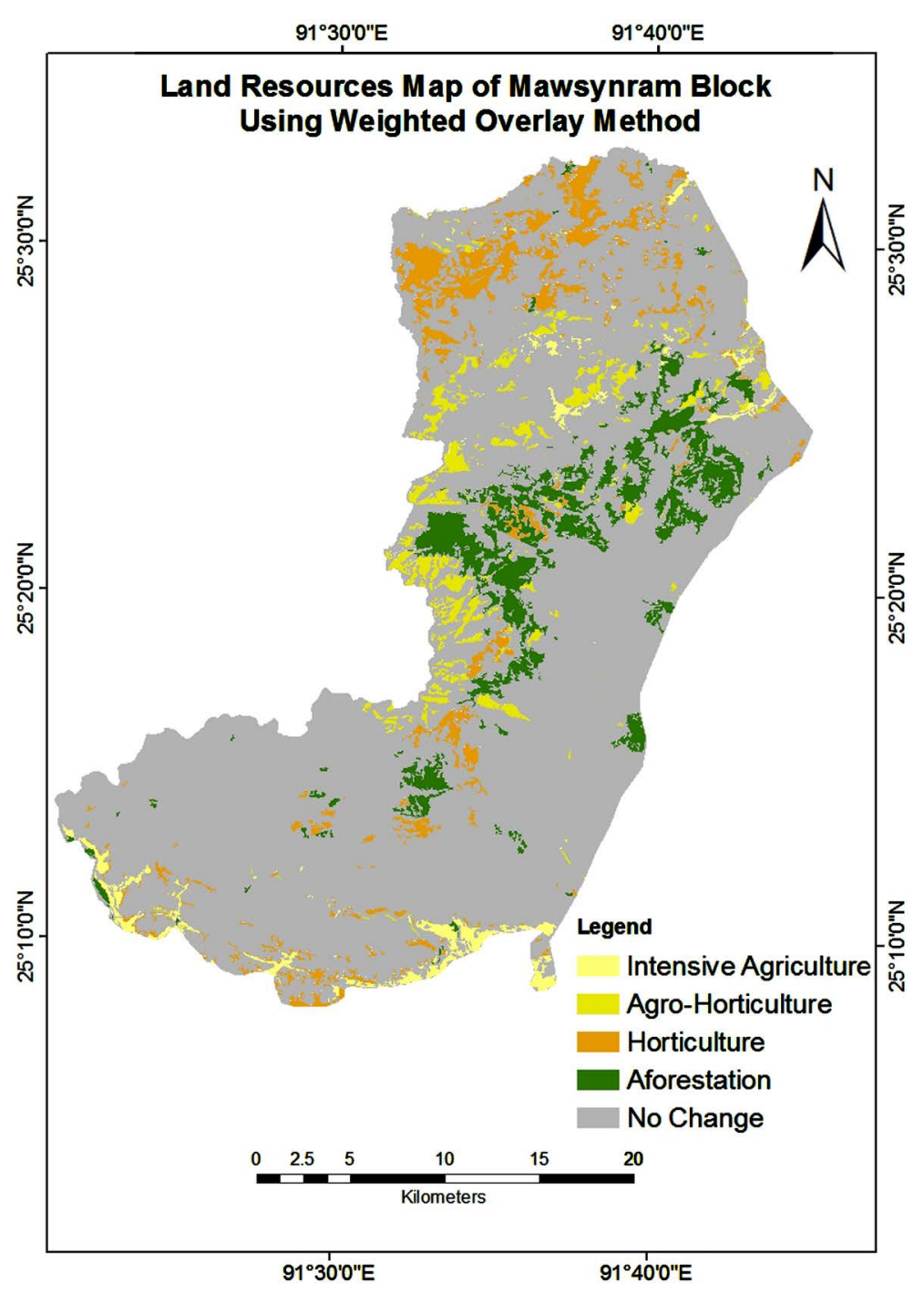

Figure 5. Land resources map using weighted overlay.

Table 2. Area statistics of land resources map derived using weighted overlay analysis.

\begin{tabular}{ccccccc}
\hline $\begin{array}{c}\text { Details on Existing Land Uses } \\
\text { and Culturable Wastelands }\end{array}$ & \multicolumn{5}{c}{ Areas (in Ha) Recommended for } \\
\hline Class & Area (Ha) & Aforestation & Agro-Horticulture & Horticulture & Intensive Agriculture & No Change \\
\hline Agricultural Land & 5860.48 & 00.00 & 989.73 & 1878.38 & 2992.37 & 00.00 \\
Culturable Wastelands & 31225.43 & 5586.23 & 2917.24 & 3133.43 & 123.86 & 19464.67 \\
Other Forest Areas & 38513.55 & 480.22 & 00.00 & 00.00 & 00.00 & 38033.33 \\
Total & 56134.79 & 6066.45 & 3906.97 & 5011.81 & 3116.23 & 38033.33 \\
\hline
\end{tabular}

The land resources map generated using fuzzy overlay is depicted in Figure 6 and the corresponding area statistics is given in Table 3. As per the analysis, most of the agricultural land is suitable for intensive agriculture (approximately 71\%). Approximately 26\% of agricultural land is recommended for horticulture, whereas only $2 \%$ of the same is recommended for expansion of agro-horticultural activity. Most of the derived culturable wastelands are found suitable for aforestation and more areas are recommended for agro-horticultural activities as compared to weighted overlay analysis. The analysis could identify approximately 763 ha of other forest 


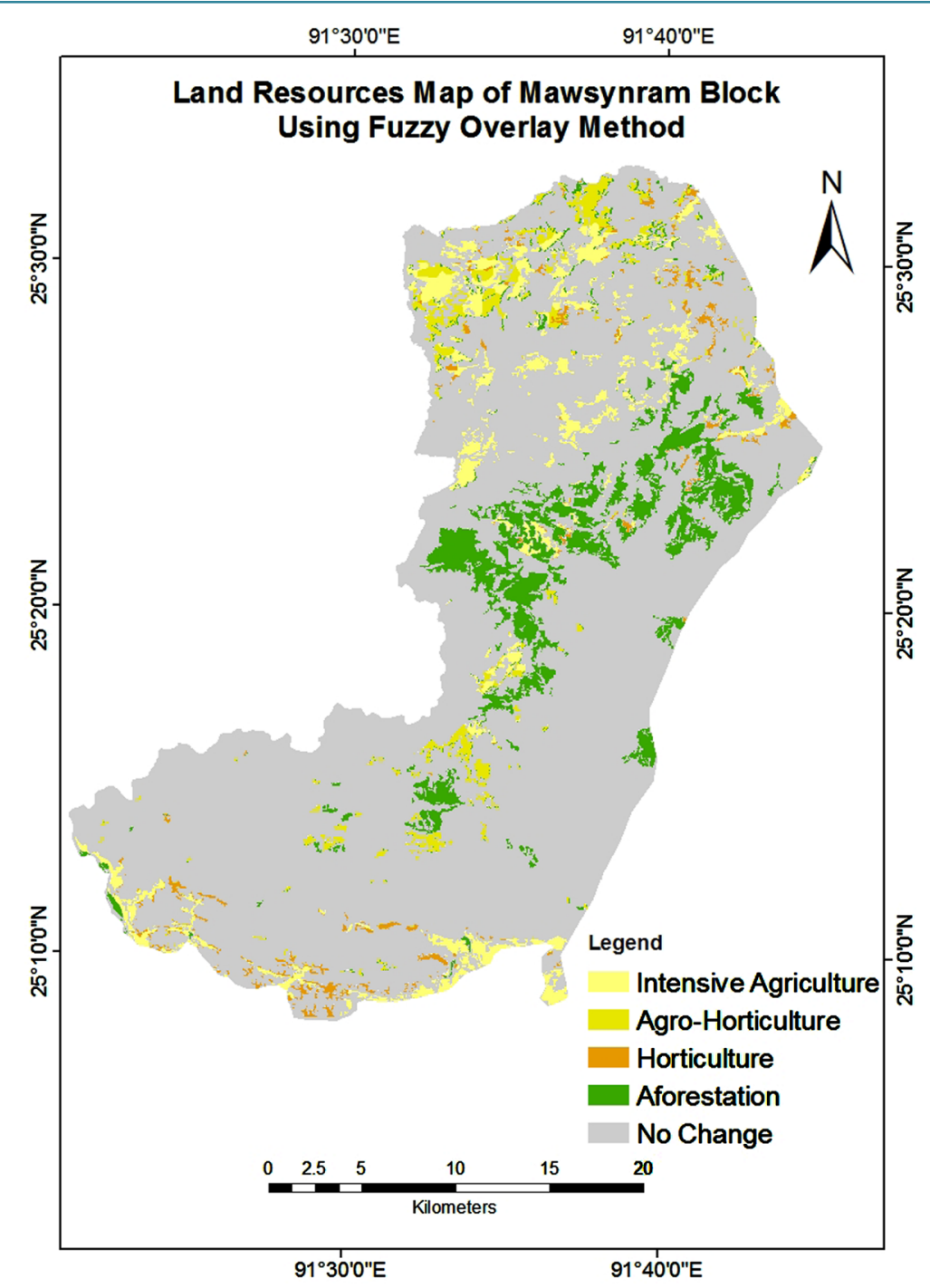

Figure 6. Land resources map using fuzzy overlay.

Table 3. Area statistics of land resources map derived using fuzzy overlay analysis.

\begin{tabular}{ccccccc}
\hline $\begin{array}{c}\text { Details on Existing Land Uses and } \\
\text { Culturable Wastelands }\end{array}$ & \multicolumn{5}{c}{ Areas (in Ha) Recommended for } \\
\hline Class & Area & Aforestation & Agro-Horticulture & Horticulture & Intensive Agriculture & No Change \\
\hline Agricultural Land & 5860.48 & 00.00 & 139.63 & 1555.17 & 4165.68 & 00.00 \\
Culturable Wastelands & 31225.43 & 4758.85 & 2604.44 & 1981.04 & 5.47 & 21902.8 \\
Other Forest Areas & 38513.55 & 762.99 & 00.00 & 00.00 & 00.00 & 37750.55 \\
Total & 53723.83 & 6521.84 & 2744.07 & 3536.21 & 4171.15 & 37750.55 \\
\hline
\end{tabular}

areas for aforestation.

Some of the experimental observations made during the investigation are illustrated below:

- Both weighted overlay and fuzzy overlay functions were effectively used for multi-criteria spatial modeling. Preparation of land resources map was demonstrated as a case study. Effectiveness of multi-criteria spatial analysis models was assessed based on the fulfillment of criteria while deriving suitable site for planning of land resources. 
- Most of the areas recommended by fuzzy overlay analysis are found fulfilling the criteria considered for potential sites as compared to weighted overlay analysis. The spatial distribution of recommended areas of land resources map derived using fuzzy overlay function is found more suitable as compared to the weighted overlay function while examining the existing input layers like land use, land capability and ground water prospects.

- Though fuzzy overlay analysis is computationally more expensive than weighted overlay analysis, but it gives more accurate and consistent results.

- In many instances, weighted overlay analysis either overestimated or underestimated the potential sites. For example, large portion of agricultural areas are wrongly recommended for horticulture, however, existing agriculture land is more suitable for intensive agriculture.

In view of all, fuzzy overlay is found to be a better alternative than other overlay functions. The result presented here is quite encouraging, but, further research is needed to improve the performance of fuzzy overlay analysis based on statistical methods and observations.

\section{Acknowledgements}

Authors are grateful to North Eastern Space Applications Centre, Dept of India, Govt. of India, Umiam-793103, Meghalaya, India for providing necessary supports during the study. Authors also acknowledged ESRI for using their software and literatures.

\section{References}

[1] Upton, G.J. and Fingelton, B. (1985) Spatial Data Analysis by Example Volume 1: Point Pattern and Quantitative Data. Biometrical Journal, 28, 664.

[2] Knox, P.L. (1980) Measure of Accessibility as Social Indicators: A Note. Social Indicators Research, 7, 367-377. http://dx.doi.org/10.1007/BF00305607

[3] Sénécal, G. (2002) Urban Spaces and Quality of Life: Moving beyond Normative Approaches. Policy Research Initiative, 5, 306-318.

[4] Goswami, J., Chutia, D. and Sudhakar, S. (2012) A Geospatial Approach to Climatic Zone Specific Effective Horticultural Planning in East Khasi Hills District of Meghalaya, India. Journal of Geographic Information System, 4, 267272. http://dx.doi.org/10.4236/jgis.2012.43032

[5] Chutia, D. (2010) Application of Geospatial Technologies for Development of an Efficient Election Management System in Meghalaya. Journal of Geomatics, 5, 115.

[6] Oledzki, J.R. (2004) Geoinformatics: An Integrated Spatial Tool, Miscellanea Geographica Warszawa. Miscellanea Geographica-Regional Studies on Development, 11, 323-331. http://www.wgsr.uw.edu.pl/pub/uploads/mcg04/35oledzki.pdf

[7] Neog, A.K. (2006) WTO and Agriculture Development in Backward Regions. In: Deb, B.J. and Ray, B.D., Eds., Changing Agriculture Scenario in North East India, Concept Publishing Company, New Delhi, 25-42. 
Scientific Research Publishing (SCIRP) is one of the largest Open Access journal publishers. It is currently publishing more than 200 open access, online, peer-reviewed journals covering a wide range of academic disciplines. SCIRP serves the worldwide academic communities and contributes to the progress and application of science with its publication.

Other selected journals from SCIRP are listed as below. Submit your manuscript to us via either submit@scirp.org or Online Submission Portal.
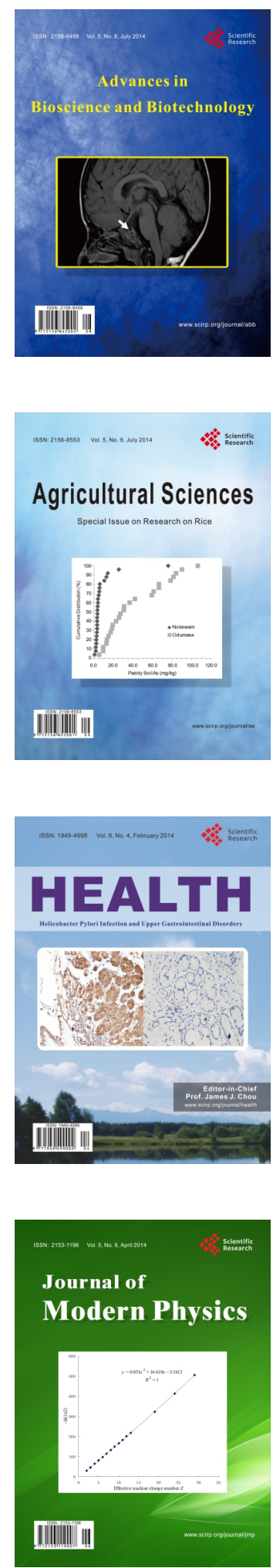
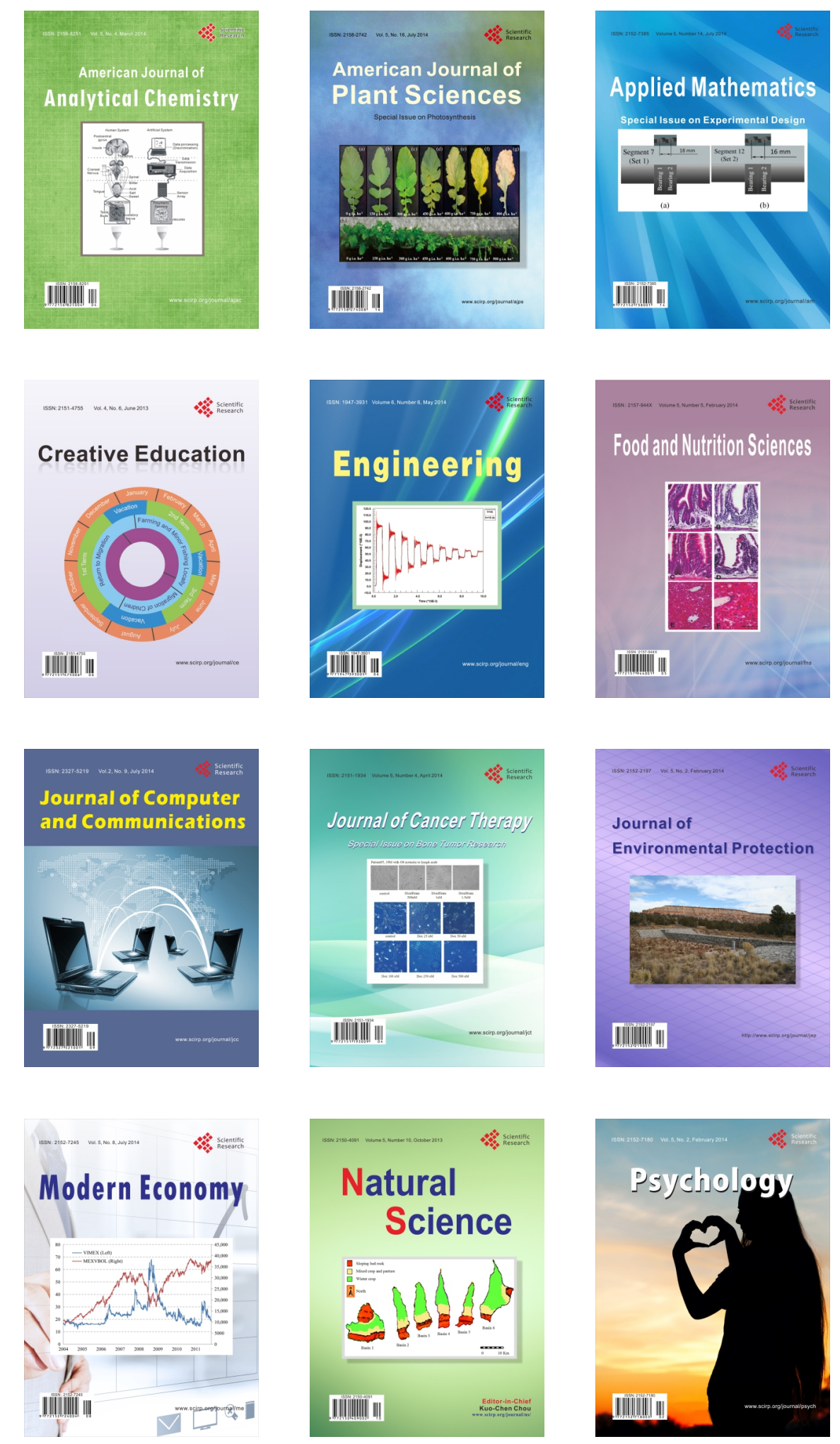